\title{
Application of Thermography in Dentistry-A Review
}

\author{
${ }^{1}$ Dr.P.E.Chandra Mouli, ${ }^{2}$ Dr (Capt).S.Manoj \\ Kumar, ${ }^{3}$ Dr.B.Senthil, ${ }^{4}$ Dr.S.Parthiban, ${ }^{5}$ Dr.A.E.Malarvizhi, ${ }^{6}$ Dr.R.Karthik \\ IReader \& Incharge, Department of Oral Medicine and Radiology, Sri Venkateswara Dental College and \\ Hospital, Thalambur, Chennai, Tamilnadu, India. \\ 2Professor, Department of Oral Medicine and Radiology, Ragas Dental College and Hospital, Chennai, \\ Tamilnadu, India. \\ 3Senior Lecturer, Department of Oral Medicine and Radiology, Asan Memorial Dental College and Hospital, \\ Keerapakkam village, Chengalpattu,Tamilnadu, India. \\ 4,5Post Graduate Students, Department of Oral Medicine and Radiology, Ragas Dental College and Hospital, \\ Chennai, Tamilnadu, India. \\ 6Senior Lecturer, Department of Oral Medicine and Radiology, Vivekananda Dental College for Women,
} Tamilnadu, India.

\begin{abstract}
Thermography is a method of measurement of skin temperature distribution on the body over a given period of time. For the past four decades, various devices have been used to measure the amount of heat dissipated by the body. The principle behind such application was built on the fact that, as the amount of blood circulation at different layers of the skin varies, the temperature also changes accordingly. Consequently, disorders that affect the blood flow too results in abnormalities in temperature distribution and these when evaluated will provide valid diagnostic information. Thermography since its inception has provided numerous dental applications; however, its usage has been abridged when compared with other diagnostic modalities. This article highlights the basics of thermography and its role in dentistry.
\end{abstract}

Keywords: Infrared, Radiative heat loss, Telethermometry, Temperature, Thermography.

\section{Introduction}

Thermology is the study and application of biothermal processes to assess health or disease and the word thermography employs imaging and visual evaluation of those thermal changes. From antiquity bodily heat is considered as an important indicator of well being and application of temperature measurement and thermal imaging had continued to evolve. Over the years, variety of devices such as thermometers, thermistors, thermocouples, and liquid crystal imaging systems have been employed to measure the body temperature. More recently, with the advancement in technology the thermography tools had progressed into a beneficiary device in diagnosis.

\section{Historical Perspective}

Body temperature evaluation dates back to Greek pre- Hippocratic medicine $(600 \pm 400 \mathrm{BC})$ and since then it is considered as a medical diagnostic sign.[1] Hippocrates in his Book of Prognostics has also mentioned that assessing the temperature at different organs and the observable asymmetries in temperature distribution can aid in the diagnosis and prognosis of medical disorders. [2]

In 1592, Galileo invented the semi quantitative air thermometer called Galileo's thermoscope, which can exhibit temperature changes. In 1611, Santorio Sanctorius modified the thermoscope and invented a thermometer, which demonstrated the variation in core temperatures of humans in both health and disease. In 1911, Wunderlich introduced fever measurements as a routine clinical diagnostic procedure. $[\mathbf{3 , 4}]$ The modern era of telethermometry was initiated in 1931 by Hardy, who described the physiological role of the infrared emission of human skin and its potential diagnostic importance. [5,6] In 1986, the American Academy of Neuro-Muscular Thermography published basic guidelines for conducting facial thermographic examinations. [7]

\section{Types Of Thermography}

Based on the method of application thermography can be classified into following types. A semi quantitative contact method that uses liquid crystals called liquid crystal thermography (LCT), a quantitative infrared-detecting non-contact method known as Infrared Telethermography (ITT) and Dynamic Area Telethermometry (DAT). 


\subsection{Liquid crystal thermography}

A liquid crystal thermometer consists of flexible rubber sheets within which cholesteric crystals are embedded. These crystals are arranged in several layers and are mounted in a frame. The sheets also have the provision for inflation, so that the heatsensitive surface conforms better to the body's contour. [8] To measure the thermal changes the crystal sheets are placed over the surfaces to be examined. After placement, the crystals changes from their neutral colour into different colour in response to the surface temperature. The resultant colour display is then photographed using Polaroid photography which gives an instant hard copy of the image. [8]

The advantages of LCT systems are that they are less expensive and portable. On the contrary, they are technique sensitive, requires timed skin contact to record a reproducible temperature distribution. Moreover, the temperatures recorded are not accurate due to the contact of the crystal sheet with the body surface which can cause compensatory warming/cooling of the contact area. The other demerits are low thermal sensitivity (0.3$1^{0} \mathrm{C}$ ) and poor spatial resolution (the separation between two nearby spots) of about $>5 \mathrm{~mm}$. [8]

\subsection{Infrared telethermography}

Infrared thermography, telethermography, telethermometry, electronic thermography, or Digital Infrared Telethermographic Imaging (DITI) is a noncontact method of temperature measurement where the detector is kept remotely at a single spot. [8] It consists of an infrared detector, amplifier- digitizer, a microcomputer and a video display. [9] The infrared detectors used here are of different types they include, single element infrared detector, linear array infrared detectors and two dimensional array detectors. [10]

The single element detector consists of a set of rapidly rotating mirrors and a germanium lens which focuses the infrared flux emitted by the subareas of the field of interest onto the mirrors as they are transparent to infrared light and have high refractive index. The single detector infrared radiation thermography works in such a way that, as the infrared radiation emitted by the face enters the germanium lens it passes through the mirrors that are placed perpendicular to each other. These set of mirrors rotates rapidly on a vertical and horizontal axis simultaneously so that every point on the field of view is scanned and reflected onto the detector which converts them into electrical signals. An amplifier then converts these electric signals into digital values which are then fed into a computer which reconstructs a digitized thermal image. [8]

An infrared camera with a linear array of detectors requires just one mirror. The mirror generally rotates around a vertical axis, to scan the field of view and hence its vertical resolution is limited. [8] Twodimensional arrays or Focal Plane Arrays (FPA) consists of a germanium lens and a plate of miniature detectors. The germanium lens functions in the same way as in single detector system and helps in focusing the infrared influxes directly on to the detectors. The advantages of the FPA cameras are that they have higher speed (allowing to obtain >100 images per second), reliability and maintenance-free performance since they require no moving parts. However, the disadvantage is limited spatial resolution. [8]

\subsection{Dynamic area telethermometry (DAT)}

Dynamic Area Telethermometry (DAT) is advancement in infrared imaging in which quantitative assessment of temperature changes (temporal thermal behaviour) over a non-uniform temperature area is measured. To record the temporal thermal behaviour, a series of thermal images are taken from each subarea. The values of each subarea unit constitute a time series of temperatures, the dynamics of which can be quantitatively analysed using fast Fourier Transform (FFT). The characteristic feature of DAT is that the FFT spectra can project the underlying temporal thermal behaviour in terms of Thermoregulatory Frequencies (TRF's). DAT thus can determine the neurogenic mediated thermal changes that follow autonomic nervous function and and provide more physiological or pathophysiological information. Another additional quality of DAT is the possibility to determine the micro spatial Homogeneity of Skin Temperature (HST) which is representation of temporal behaviour of cutaneous perfusion. [8-11]

\section{General Clinical Requirements}

Thermography procedure is painless, non-invasive procedure that can be done within minutes and requires the following: A trained telethermographer and a high-quality telethermography system consisting of infrared camera, thermal control unit and image analysis software. The examining room should be of approximately 8 feet by 10 feet to maintain a uniform temperature. The room must be free from drafts, carpeted and curtains should be used to prevent outside infrared radiation from entering the room. Windows and doors should be adequately sealed to prevent airflow in the area where the patient is positioned. Standard fluorescent lighting is adequate and incandescent lighting should not be used during the examination due to the amount of infrared radiation it produces. During the examination, the patient should be positioned relatively equidistant and adequately spaced from each wall. $[\mathbf{1 2 , 1 3}]$

The examining room must have a thermometer to evaluate the temperature of the room. The room temperature should be maintained between $18-23^{\circ} \mathrm{C}$ and should not vary more than one degree Celsius during 
the course of the study. The humidity of the room should also be controlled (30-70\%) such that there is no moisture build up on the skin, perspiration or vapour levels that can interact with radiant infrared energy. $[12,13]$ Prior to examination patients with minor infections in and around the face should be recorded like those occurring with pimples, razor nicks etc., as they can interfere with the diagnosis and can appear as hyperthermic artifacts. Similarly facial scars can appear as pathological hypothermic lesions. Patients with fever and with sunburn are not eligible for accurate thermal image analysis, in such cases it is advisable to defer telethermographic facial studies until the acute phase subsides.

Similarly before examination the patient's face must be cleared from lotions, creams, powders, deodorants or antiperspirants on the area to be imaged as it can effect on skin reflectivity. No physical therapy, ultrasound treatment, acupuncture or hot/cold pack should be used 24 hours prior to the examination. The examining body area should not be shaved four hours and patient should not bathe for an hour before examination. Before the commencement of the procedure the hair must be pulled back from the face with an elastic head band, all clothing and jewellery at the site of examination should be removed. The patient should be allowed to sit in a relaxed position for a minimum of 15 minutes ahead of examination to allow for a stable physiologic behaviour. The hand held electric fan can be used for 25 seconds to cool the face before initiation of the procedure. $[12,13]$

\section{Clinical Application Of Thermography}

Thermography measurement in the clinical set up can be done on a given spot or over an extended area of interest. The former method is called static thermography and the latter is dynamic thermography. Infrared telethermography of the face in normal subjects have shown that men have higher temperatures than females. The rationale behind this is that men have more basal metabolic than women and his skin dissipates more heat per unit area of body surface. Similarly age and ethnicity variations in facial temperature can also occur. [14-16]

\subsection{In Chronic Orofacial pain patients}

Gratt and his colleagues in 1996 developed a classification system using telethermographs for patients with chronic pain. [17] They classified them as normal when selected anatomic area $(\Delta \mathrm{T})$ values range from 0.0 to $+0.25^{\circ} \mathrm{C}$, hot when it is $>0.35^{\circ} \mathrm{C}$, and cold when it is $<0.35^{\circ} \mathrm{C}$. When a selected anatomic area value is 0.26 $0.35^{\circ} \mathrm{C}$, the finding is classified as equivocal.

Moreover they also found that hot thermographs had the clinical diagnosis of (1) sympathetically maintained pain, (2) peripheral nerve mediated pain, (3) TMJ arthropathy, or (4) maxillary sinusitis. Subjects classified with cold subareas on their thermographs were found to have the clinical diagnosis of (1) peripheral nerve-mediated pain (2) sympathetically independent pain. Subjects classified with normal telethermographs included patients with the clinicaldiagnosis of (1) cracked tooth syndrome (2) trigeminal neuralgia (3) pretrigeminal neuralgia (4) psychogenic facial pain. This new system of thermal classification resulted in $92 \%$ agreement in classifying pain patients making it as an important diagnostic parameter. [12,17]

\subsection{In TMJ disorders}

Normal TMJ examination using thermography had showed symmetrical thermal patterns with a mean $\Delta \mathrm{T}$ values of $0.1^{\circ} \mathrm{C}$. $[12, \mathbf{1 4}, \mathbf{1 8}]$ On the other hand, patients affected with internal derangement and TMJ osteoarthritis showed $\Delta \mathrm{T}$ values of $+0.4^{0} \mathrm{C}$. [19, 20] Beth and Gratt in 1996 conducted a double-blinded clinical study to compare the $\Delta \mathrm{T}$ values among active orthodontic patients, TMD patients and asymptomatic TMJ controls. The results showed that the average TMJ area $\Delta \mathrm{T}$ values as $+0.2^{0} \mathrm{C},+0.4^{\circ} \mathrm{C}$, and $+0.1^{\circ} \mathrm{C}$ in these groups respectively.(21) The above findings suggest that tele-thermography can distinguish between patients undergoing active orthodontic treatment and patients with TMD. [12,21]

\subsection{In quantification of thermal insult to pulp}

Dental pulpal tissue is exposed to variety of thermal insult during various dental treatment modalities. Of late for debonding of orthodontic brackets Eelectro Thermal Ddebonding (ETD) method is widely used, this technique although has many advantages than the conventional mechanical method can pose serious thermal damage to pulp. Cummings and his colleagues in 1999 performed an in-vitro study on extracted human premolar teeth applying ETD. Thermal imaging analysis was done using mercury cadmium terullide detector showed that the pulpal temperature increased from $16.8^{\circ} \mathrm{C}-45.6^{\circ} \mathrm{C}$, which can pose serious threat to pulpal vitality. It can be stated from the study that, ETD methods needs intermittent cooling of the teeth with simultaneous thermal imaging to prevent pulpal damage. [22] Similarly the use of ultra high speed air-driven instrumentation during cavity preparation can result in serious thermal insult to the pulp. To overcome this, it is believed that various coolants (air water spray or air/water alone) can be used to reduce the intrapulpal temperature and prevent subsequent damage to the pulp. It was only until 1979, when Carson and his colleagues performed a study employing thermography to determine the pattern of heat distribution and dissipation during ultra-speed cavity preparation using both an air-water spray and air only coolants to determine if a point heat 
source is generated. This study stated that the mean magnitude of temperature increases with both types of coolant, $2.8^{\circ} \mathrm{C}$ and $3.67^{\circ} \mathrm{C}$, probably does not exceed the physiologic limits of the pulp. [23]

\subsection{In assessing inferior alveolar nerve deficit}

Over the years numerous studies have shown that thermal imaging technique can play an vital role in effective assessment of inferior alveolar nerve deficit. [12,24] Gratt and his colleagues in 1994 stated that patients with inferior alveolar nerve deficit when examined showed $\Delta \mathrm{T}$ values of $+0.5^{\circ} \mathrm{C}$ on the affected side whereas subjects with no inferior alveolar nerve deficit showed a symmetrical thermal $\Delta \mathrm{T}$ value of $+0.1^{\circ} \mathrm{C}$. [25] The authors stated that the changes are due to blockage of the vascular neuronal vasoconstriction and this was confirmed by the same colleagues in the same year when similar thermological picture was obtained in normal subjects by temporary blockage of the inferior alveolar nerve using $2 \%$ lidocaine. [26]

\subsection{Qualitative evaluation of $\mathrm{N}_{2} \mathrm{O}$ concentration}

$\mathrm{N}_{2} \mathrm{O}$ is a highly insoluble gas which is rapidly absorbed is eliminated swiftly by the lungs, thus it is used widely either alone or in combination with other anesthetic agents. [27] Results of various studies have shown that leakage of $\mathrm{N}_{2} \mathrm{O}$ into the workplace can lead to adverse health effects such as reproductive, hematologic and nervous dysfunctions. [28] Studies on acute and chronic occupational exposures have shown that $\mathrm{N}_{2} \mathrm{O}$ air concentration levels as low as 50 parts per million ( $\mathrm{ppm}$ ) can result in bone marrow depression, paresthesias, altered concentration, impaired visual effects, alterations in vitamin B12 and plasma homocysteine concentrations. [29-31]

In response to these findings and in order to effectively control exposures several guidelines have been published that define appropriate use and control criteria for $\mathrm{N}_{2} \mathrm{O}$ usage. The ADA made 10 recommendations that address the use of appropriate engineering controls for proper scavenging. [32] However, they are proved futile and health hazards secondary to $\mathrm{N}_{2} \mathrm{O}$ exposure is still on the rise. Rademaker et al in 2009 conducted a study using infrared thermography to determine the effectiveness of two $\mathrm{N}_{2} \mathrm{O}$ scavenging systems- The Safe Sedate Dental Mask (Airgas, Radnor, Pa.) system (System I) and Porter Nitrous Oxide Sedation System (Porter Instrument, Hatfield, Pa.) (System II). The results suggested that neither of the system was able to control occupational exposure of $\mathrm{N}_{2} \mathrm{O}$ oxide below the NIOSH REL. [33]

\subsection{Additional applications of telethermography}

- Evaluation of cranio mandibular disorders. [34]

- Detection of carotid occlusal disease. [35]

- Quantification of the effects of post-surgical inflammation. [36]

- Quantification of the effects of analgesics, anti-inflammatory drugs, etc.

- In the diagnosis of myofacial symptoms.

\section{Conclusion}

Thermography aids in the assessment and staging of various dysfunctions of the head and neck region. The unique significance of thermography is both qualitative and quantitative assessment which helps in estimation of progression of the disease in a systematic manner. With the innovation of novel equipments and the state of the art facility, thermography in the near future will certainly re-emerge as a unique research tool in dentistry.

\section{References}

[1] Anbar M. Diagnostic thermal imaging: A historical technological perspective. In: Anbar M (ed). (Quantitative Dynamic Telethermography in Medical Diagnosis. CRC Press: BocaRaton. 1994), pp 1-9.

[2] Adams F. Hippocratic Writings, In: Hutchins RM (ed). (Hippocrates, Galen, Vol. 10 of Great Books of the Western World, Univ. of Chicago, Encyclopedia Britannica Inc. 1952),pp 66-77.

[3] Wolf A. A History of Science and Technology and Philosophy in the 16th \& 17th Centuries. 2nd ed., McKee D (ed). George Allen \& Unwin: London. 1950, pp 66-77.

[4] Bedford RE. Thermometry. In: The New Encyclopedia Britannica, 15th ed, Chicago. Ill. 1992; 11: 702-703.

[5] Hardy JD. The radiation of heat from the human body: I-IV. J Clin Invest. 1934; 13: 593-620.

[6] Hardy JD, Muschenheim C. The radiation of heat from the human body: V. J Clin Invest. 1936; 15: 1-8.

[7] Weinstein SA. Standards for neuromuscular thermographic examination. Modern Medicine: Supplement. 1986; 1: 5-7.

[8] Anbar M, Gratt BM, Hong D. Thermology and facial telethermography. Part I: history and technical review. Dento maxillofac Radiol. 1998; 27: 61-67.

[9] Anbar M. Fundamentals of computerized thermal imaging. In: Anbar M. Quantitative Dynamic Telethermography in Medical Diagnosis. CRC Press: Boca Raton. 1994, pp 99-131.

[10] Anbar M. Dynamic area telethermometry: a new field in clinical thermology: Part II. Medical Electronics. 1994; 147: 73-85.

[11] Anbar M. Dynamic area telethermometry and its clinical applications. SPIE Proc. 1995; 2473: 312-331

[12] Gratt BM, Anbar M. Thermology and facial telethermography: Part II: Current and future clinical applications in dentistry. Dento maxillofac Radiol. 1998; 27: 68-74. 
[13] Ongole R, Praveen BN. Chapter 21- Specialized imaging techniques. In: Clinical manual for Oral Medicine and Radiology. Jaypee Brothers, New Delhi. 2007, pp 439-441.

[14] Gratt BM, Sickles EA. Electronic facial thermography: an analysis of asymptomatic adult subjects. J Orofacial Pain. 1995; 9: 255 265.

[15] Blaxter K. Energy exchange by radiation, convection, conduction, and evaporation. In: Energy Metabolism in Animals and Man Cambridge Univ. Press: New York, 1989: pp 86- 99.

[16] Blaxter K. The minimal metabolism. In: Energy Metabolism in Animals and Man. Cambridge Univ. Press: New York, 1989, pp $120-146$.

[17] Gratt BM, Graff-Radford SB, Shetty V, Solberg WK, Sickles EA. A six-year clinical assessment of electronic facial thermography Dentomaxillofac Radiol. 1996; 25: 247 -255.

[18] Gratt BM, Sickles EA. Thermographic characterization of the asymptomatic TMJ. J Orofacial Pain. 1993; 7: 7-14.

[19] Gratt BM, Sickles EA, Ross JB. Thermographic characterization of an intemal derangement of the temporomandibular joint. J Orofacial Pain. 1994; 8: 197-206.

[20] Gratt BM, Sickles EA, Wexler CA. Thermographic characterization of osteoarthrosis of the temporomandibular joint. J Orofacial Pain. 1993; 7: 345-353.

[21] McBeth SA, Gratt BM. A cross-sectional thermographic assessment of TMJ problems in orthodontic patients. Am J Orthod Dentofac Orthop. 1996; 109: 481-488.

[22] Cummings M, Biagioni P, Lamey PJ, Burden DJ. Thermal image analysis of electrothermal debonding of ceramic brackets: an in vitro study. European Journal of Orthodontics. 1991; 21: 111-118.

[23] Carson J, Rider T, Nash D. A Thermographic Study of Heat Distribution during Ultra-Speed Cavity preparation. J Dent Res. 1979; $58 ; 16-81$.

[24] Gratt BM, Shetty V, Saiar M, Sickles EA. Electronic thermography for the assessment of inferior alveolar nerve deficit. Oral Surg Oral Med Oral Pathol. 1995; 80: 153-160.

[25] Gratt BM, Sickles EA, Shetty V. Thermography for the clinical assessment of inferior alveolar nerve deficit: A pilot study. J Orofacial Pain. 1994; 8: 369- 374.

[26] Shetty V, Gratt BM, Flack V. Thermographic assessment of reversible inferior alveolar nerve deficit. J Orofacial Pain. 1994; 8: 375 383.

[27] Emmanouil DE, Quock RM. Advances in understanding the actions of nitrous oxide. Anesth Prog. 2007; 54(1):9-18.

[28] Cohen EN, Brown BW Jr, Bruce DL, et al. A survey of anesthetic health hazards among dentists. JADA. 1975; 90(6):1291-1296.

[29] McGlothlin JD, Crouch KG, Mickelsen RL. Control of nitrous oxide in dental operatories. Cincinnati: National Institute for Occupational Safety and Health; U.S. Department of Health and Human Services (NIOSH) publication. 1994; 94-129.

[30] Krajewski W, Kucharska M, Pilacik B, et al. Impaired vitamin B12 metabolic status in healthcare workers occupationally exposed to nitrous oxide. Br J Anaesth. 2007;99(6):812-818.

[31] Myles PS, Chan MT, Leslie K, Peyton P, Paech M, Forbes A. Effect of nitrous oxide on plasma homocysteine and folate in patients undergoing major surgery. Br J Anaesth. 2008; 100(6):780-786.

[32] ADA Council on Scientific Affairs; ADA Council on Dental Practice. Nitrous oxide in the dental office. JADA. 1997; 128(3):364365.

[33] Rademaker MA et al. Evaluation of Two Nitrous Oxide Scavenging systems Using Infrared Thermography to Visualize and Control Emissions. J Am Dent Assoc. 2009; 140; 190-199.

[34] Biagioni PA, Longmore RB, McGimpsey JG, Lamey PJ. Infrared thermography. Its role in dental research with particular reference to craniomandibular disorders. Dentomaxillofac Radiol. 1996; 25: 119-124.

[35] Friedlander AH, Gratt BM. Panoramic dental radiography and thermography as an aid in detecting patients at risk for stroke. J Oral Maxillofac Surg. 1994; 52: 1257- 1262.

[36] Sudhakar S, Bina kayshap, Sridhar reddy P. Thermography in dentistry-revisited. Int J Biol Med Res. 2011; 2(1): 461-465 